\title{
Multivariate Analysis of Some Clinical Parameters by Gender and Age in Patients with COPD for the First Time Diagnosed
}

\author{
Seha AKDUMAN, Yusuf SAHIIP \\ Yeditepe Üniversitesi Koşuyolu Hastanesi, Koşuyolu, İstanbul/Kadıöy, İstanbul, TURKEY \\ Corresponding Author: Seha AKDUMAN; akdumanseha@hotmail.com
}

Received 21 August 2019;

Accepted 15 September 2019;

Published 26 September 2019

\begin{abstract}
Aim: In this study, it was aimed to analyze the different clinical parameters according to gender and age for the first time in patients diagnosed with COPD. Methods: The study was designed retrospectively. Patients who were admitted to Kadikoy Medicana Hospital between 12.10.2017 and 12.10.2018 with respiratory complaints and COPD diagnosed for the first time were included in the study. A total of 160 patients with the diagnosis of COPD for the first time among 845 patients were included in the study. Age, gender, urea, creatinine, CRP, NEU, WBC, EOS and HGB values were obtained from the patient files. Findings: Clinical parameters of CRP, urea, creatinine, WBC, NEU and HGB were higher in male patients and EOS was higher in female patients. According to the results of the difference analysis, only HGB levels were statistically different between the groups $(\mathrm{p}<0.05)$. According to uncontrolled gender correlation analysis in patients with COPD for the first time, CRP $(\mathrm{r}=$ 0.224; $\mathrm{p}<0.01)$, urea $(\mathrm{r}=0.580 ; \mathrm{p}<0.01)$, creatinine $(\mathrm{r}=0.331 ; \mathrm{p}<0.01)$, creatinine $(\mathrm{r}=0.331 ; \mathrm{p}<0.01)$, EOS $(\mathrm{r}=-0.172 ; \mathrm{p}<0.05)$ and HGB $(\mathrm{r}$ $=-0.319 ; \mathrm{p}<0.01)$ level correlations with age were statistically significant. There was a positive correlation between CRP, urea and creatinine and age, and there was a negative correlation between EOS and HGB and age. Age and urea $(r=0.573 ; p<0.01)$ and creatinine $(r=0.426 ; p$ $<0.01)$ were statistically significant and positively correlated in women with firstly diagnosed COPD. Correlations between age and other research parameters were not statistically significant ( $p>0.05)$. CRP $(r=0.300 ; p<0.01)$, urea $(r=0.565 ; p<0.01)$, creatinine $(r=295 ; p<0.05)$, creatinine $(r=295 ; p<0.05)$, EOS $(r=-0.225 ; p<0.05)$ and HGB $(r=-0.372 ; p<0.01)$ were significantly correlated in male patients who firstly diagnosed with COPD. The direction of the correlation was positive for CRP, urea and creatinine, and negative for EOS and HGB parameters. Conclusion: The results of the study show that age and urea and creatinine levels of the women with COPD diagnosis for the first time have changed according to age. In males, CRP, urea, creatinine, EOS and HGB values change according to age. Therefore, it is useful to study gender and age-related mechanisms in COPD.
\end{abstract}

Keywords: COPD, gender, age, urea, creatinine, CRP, blood count.

\section{Introduction}

Chronic Obstructive Pulmonary Disease (COPD), a common disease of pulmonary medicine, is known by aspiration of gastric juice during respiration as well as physical symptoms and debilitating progression. ${ }^{[1,2,3]}$ National Institute of Health (NIH) reported the disease as a leading cause of mortality in the United States. ${ }^{[4]}$ COPD has a debilitating and slow progression with physical symptoms. ${ }^{[5]}$ COPD causes airflow restriction and changes in lung, and for this reason, it is associated with comorbidities and systemic effects. ${ }^{[6,7,8]}$

The management of COPD is mainly depend on progression inhibiting strategy. ${ }^{[9,10,11,12]}$ Since treatment methods are restricted, prevention of COPD is as important as treatment. For this reason, risk factors of the COPD must be well understood. In this study, it was aimed to analyze the different clinical parameters according to gender and age for the first time in patients diagnosed with COPD.

\section{Methods}

The study was designed retrospectively. Patients who were admitted to Kadikoy Medicana Hospital between 12.10.2017 and 12.10.2018 with respiratory complaints and COPD diagnosed for the first time were included in the study. A total of 160 patients with the diagnosis of COPD for the first time among 845 patients were included in the study. The inclusion criteria were as follows:

\footnotetext{
With any respiratory complaints,

For the first time diagnosed with COPD,

- No long-term drug use which may affect steroid and similar research data,

Clinically without heavy table.
} 
Age, gender, urea, creatinine, CRP, NEU, WBC, EOS and HGB values were obtained from the patient files. Data were taken from the last follow-up of blood samples with urea and creatinine tests.

In the analysis of the research data, Kolmogorov Smirnov test was performed for the distribution of the measurement data. At the end of the test, Independent Samples TTest was applied for the difference between the normal distribution age, WBC and HGB data. Mann-Whitney-U test was applied for the parameters that did not comply with normal distribution (CRP, urea, creatinine, NEU and EOS). Spearman's rho correlation analysis was used for correlated and uncontrolled analyzes with partial correlation method. All analyzes were analyzed with SPSS 17.0 for Windows and 0.05 significance level.

\section{Results}

The mean age of the subjects included in the study and the distribution of some clinical parameters are given in Table 1.

Table 1: Baseline characteristics of patients and differences based on gender

\begin{tabular}{llll}
\hline $\begin{array}{l}\text { Parameter, } \\
\text { Mean } \pm \text { SD }\end{array}$ & $\begin{array}{l}\text { Female } \\
(\mathbf{n = 7 3})\end{array}$ & $\begin{array}{l}\text { Male } \\
(\mathbf{n}=\mathbf{8 7})\end{array}$ & $\mathbf{p}$ \\
\hline Age & $\mathbf{7 0 . 3 3} \pm \mathbf{1 4 . 5 4}$ & $67.88 \pm 12.60$ & $0.257^{\mathrm{a}}$ \\
CRP & $1.57 \pm 2.59$ & $\mathbf{1 . 8 1} \pm \mathbf{3 . 5 3}$ & $0.376^{\mathrm{b}}$ \\
Urea & $46.33 \pm 27.15$ & $\mathbf{4 6 . 4 5} \pm \mathbf{3 3 . 1 8}$ & $0.211^{\mathrm{b}}$ \\
Creatine & $0.84 \pm 0.32$ & $\mathbf{0 . 9 2} \pm \mathbf{0 . 4 1}$ & $0.055^{\mathrm{b}}$ \\
WBC & $8.59 \pm 3.07$ & $\mathbf{8 . 7 3} \pm \mathbf{3 . 5 6}$ & $0.800^{\mathrm{a}}$ \\
NEU & $5.84 \pm 2.86$ & $\mathbf{6 . 0 6} \pm \mathbf{3 . 4 5}$ & $0.956^{\mathrm{b}}$ \\
EOS & $\mathbf{0 . 2 0} \pm \mathbf{0 . 2 1}$ & $0.20 \pm 0.20$ & $0.833^{\mathrm{b}}$ \\
HGB & $12.94 \pm 1.63$ & $\mathbf{1 3 . 9 7} \pm \mathbf{2 . 0 6}$ & $\mathbf{0 . 0 0 1}^{\mathrm{a}}$ \\
\hline
\end{tabular}

a. Independent Samples T-Test, b. Mann Whitney-U test.

The mean age of women $(70.33 \pm 14.54)$ who were first diagnosed with COPD was greater than the mean age of men $(67.88 \pm 12.60)$. However, according to the results of the difference analysis, these differences between the average age of female and male patients were not statistically significant $(p>0.05)$. Clinical parameters of CRP, urea, creatinine, WBC, NEU and HGB were higher in male patients and EOS was higher in female patients. According to the results of the difference analysis, only HGB levels were statistically different between the groups $(\mathrm{p}<0.05)$. The difference between the other parameters was not statistically significant $(p>$ $0.05)$. The results of gender controlled and $g$ uncontrolled Spearman's rho correlation analysis between age and clinical parameters are presented in Table 2.

Table 2: Gender controlled and uncontrolled correlation results between age and parameters

\begin{tabular}{lllll}
\hline Age & \multicolumn{2}{l}{ Uncontrolled } & \multicolumn{2}{l}{ Controlled } \\
\cline { 2 - 5 } & r & $\mathbf{P}$ & r & $\mathbf{p}$ \\
\hline CRP & 0.224 & $\mathbf{0 . 0 0 7}$ & 0.260 & $\mathbf{0 . 0 0 6}$ \\
Urea & 0.580 & $\mathbf{0 . 0 0 0}$ & 0.417 & $\mathbf{0 . 0 0 0}$ \\
Creatine & 0.331 & $\mathbf{0 . 0 0 0}$ & 0.328 & $\mathbf{0 . 0 0 0}$ \\
WBC & 0.017 & 0.832 & 0.188 & $\mathbf{0 . 0 4 8}$ \\
NEU & 0.107 & 0.179 & 0.230 & $\mathbf{0 . 0 1 5}$ \\
Eos & -0.172 & $\mathbf{0 . 0 3 0}$ & 0.023 & 0.813 \\
HGB & -0.319 & $\mathbf{0 . 0 0 0}$ & -0.323 & $\mathbf{0 . 0 0 1}$ \\
\hline
\end{tabular}

According to gender uncontrolled correlation analysis in patients with COPD for the first time, CRP $(r=0.224 ; \mathrm{p}<0.01)$, urea $(\mathrm{r}=$ $0.580 ; \mathrm{p}<0.01)$, creatinine $(\mathrm{r}=0.331 ; \mathrm{p}<0.01)$, creatinine $(\mathrm{r}=$
$0.331 ; \mathrm{p}<0.01)$, EOS $(\mathrm{r}=-0.172 ; \mathrm{p}<0.05)$ and HGB $(\mathrm{r}=-0.319 ; \mathrm{p}$ $<0.01)$ level correlations with age were statistically significant. There was a positive correlation between CRP, urea and creatinine and age, and there was a negative correlation between EOS and HGB and age.

According to gender controlled gender correlation analysis in patients with COPD for the first time, CRP $(r=0.260$; $p$ $<0.01)$, urea $(\mathrm{r}=0.417$; $\mathrm{p}<0.01)$, creatinine $(\mathrm{r}=0.328$; $\mathrm{p}<0.01)$, WBC $(r=0.188 ; \mathrm{p}<0.05)$, NEU $(r=0.230 ; \mathrm{p}<0.05)$, and HGB $(\mathrm{r}=-$ $0.323 ; \mathrm{p}<0.01)$ level correlations with age were statistically significant. There was a positive relationship between CRP, urea, creatinine, WBC and NEU, and there was a negative correlation between HGB and age. The results of the Spearman's rho correlation analysis for the relationship between age and clinical parameters based on gender groups were given in Table 3 .

Table 3: Correlation results between age and parameters based on gender

\begin{tabular}{lllll}
\hline & \multicolumn{2}{l}{ Female $(\mathbf{n}=\mathbf{7 3})$} & \multicolumn{2}{l}{ Male $(\mathbf{n}=\mathbf{8 7})$} \\
\cline { 2 - 5 } & $\mathbf{R}$ & $\mathbf{p}$ & $\mathbf{r}$ & $\mathbf{p}$ \\
\hline CRP & 0.137 & 0.263 & 0.300 & $\mathbf{0 . 0 0 9}$ \\
Urea & 0.573 & $\mathbf{0 . 0 0 0}$ & 0.565 & $\mathbf{0 . 0 0 0}$ \\
Creatine & 0.426 & $\mathbf{0 . 0 0 1}$ & 0.295 & $\mathbf{0 . 0 1 0}$ \\
WBC & -0.008 & 0.950 & 0.040 & 0.716 \\
NEU & 0.078 & 0.514 & 0.144 & 0.182 \\
EOS & -0.106 & 0.373 & -0.225 & $\mathbf{0 . 0 3 7}$ \\
HGB & -0.215 & 0.068 & -0.372 & $\mathbf{0 . 0 0 0}$ \\
\hline
\end{tabular}

Age and urea $(r=0.573 ; \mathrm{p}<0.01)$ and creatinine $(\mathrm{r}=0.426 ; \mathrm{p}$ $<0.01$ ) were statistically significant and positively correlated in women with firstly diagnosed COPD. Correlations between age and other research parameters were not statistically significant $(\mathrm{p}>$ $0.05)$.

CRP ( $\mathrm{r}=0.300 ; \mathrm{p}<0.01)$, urea $(\mathrm{r}=0.565 ; \mathrm{p}<0.01)$, creatinine $(r=295 ; p<0.05)$, creatinine $(r=295 ; p<0.05)$, EOS $(r$ $=-0.225 ; \mathrm{p}<0.05)$ and HGB $(\mathrm{r}=-0.372 ; \mathrm{p}<0.01)$ were significantly correlated in male patients who firstly diagnosed with COPD. The direction of the correlation was positive for CRP, urea and creatinine, and negative for EOS and HGB parameters.

\section{Discussion}

In the literature, there are studies reporting that the prevalence of COPD is generally positively correlated with age and more common in men (12-15). In these studies, males are reported to have higher COPD susceptibility due to working conditions and environmental factors and smoking (16-19). On the other hand, there are studies reporting that biomass exposure, especially in rural areas, has a high prevalence of COPD in women (20-22). In our study, although only the difference of HGB parameter was found to be statistically significant, overall clinical picture was more severe in men than in women.

Although there are studies in the literature that examined gender, age and similar demographic characteristics for COPD patients (23-27), there is not enough study on the relationship between these variables in controlled manner. Correlation analysis revealed that there was a statistically significant relationship between CRP, urea, creatinine, EOS, and HGB in COPD patients. In the correlation analysis in which gender was controlled, all parameters except EOS were statistically significantly correlated with age. In other words, when the gender was taken into consideration, WBC and NEU parameters were also significantly correlated with age. 
When the correlation analysis is done separately for women and men; While CRP, urea, creatinine, EOS and HGB age were statistically significantly correlated with age in males, there was a statistically significant correlation between age and urea and creatinine age in females.

\section{Conclusion}

Although there are studies investigating age and gender in patients with COPD, there are not enough studies in which these two variables are controlled. In addition, it can be stated that the mechanism of effect of age and gender has not been adequately examined in the literature.

The results of the study show that age and urea and creatinine levels of the women with COPD diagnosis for the first time have changed according to age. In males, CRP, urea, creatinine, EOS and HGB values change according to age. Therefore, it is useful to study gender and age-related mechanisms in COPD.

\section{References}

1. Laraeau SC, Fahy B, Meek P and Wang A. (2019). "Chronic Obstructive Pulmonary Disease (COPD)". Am J Respir Crit Care Med Vol. 199, P1-P2

2. Seemungal T, Donaldson G, Bhowmik A, Jeffries DJ, Wedzicha JA. Time course and recovery of exacerbations in patients with chronic obstructive pulmonary disease. Am J Respir Crit Care Med. 2000;161:1608-1613.

3. Bourbeau J, Julien M, Maltais F, Rouleau M, Beaupré A, Bégin $\mathrm{R}$, et al. Reduction of hospital utilization in patients with chronic obstructive pulmonary disease: a disease-speci\$c self-management intervention. Arch Intern Med. 2003 Mar 10;163(5):585-91.

4. National Institutes of Health. COPD National Action Plan. 2017.

5. Landers A, Wiseman R, Pitama S, et al. Severe COPD and the transition to a palliative approach. Breathe 2017; 13: $310-316$.

6. Prosser TR and Bolmeier SG. (2008). "Chronic Obstructive Pulmonary Disease". Pharmacotheraphy Self-Assesment Program, 6th Edition.

7. Couillard S, Larivee P, Courteau J and Vanasse A. (2017). "Eosinophils in COPD Exacerbations Are Associated With Increased Readmissions". Chest, 151(2), 366-373.

8. Restrepo MI, Sibila O, Anzueto A. Pneumonia in Patients with Chronic Obstructive Pulmonary Disease. Tuberc Respir Dis 2018;81:187-197.

9. Mackay, A. J., \& Hurst, J. R. (2012). COPD Exacerbations: Causes, prevention, and treatment. Medical Clinics of North America, 96(4), 789-809.

10. Seemungal TA, Donaldson GC, Paul EA, Bestall JC, Jeffries DJ, Wedzicha JA. Effect of exacerbation on quality of life in patients with chronic obstructive pulmonary disease. Am J Respir Crit Care Med 1998;157(5 Pt 1):1418-22.

11. Jeong SW, Lee JH, Choi KJ, Hwangbo Y, Kim YY, Lee $\mathrm{YG}$, et al. Comparisons of clinical characteristics and outcomes in COPD patients hospitalized with community-acquired pneumonia and acute exacerbation. Zhonghua Jie He He Hu Xi Za Zhi. 2010;69:31-8.
12. Roberts NJ, Patel IS and Partridge MR. (2016). "The diagnosis of COPD in primary care; gender differences and the role of spirometry". Respiratory Medicine, 111(1), 60-63.

13. Delgado A, Saletti-Cuesta L, Lopez-Fernandez LA, GilGarrido N and Castillo JDL. (2016). "Gender inequalities in COPD decision-making in primary care”. Respiratory Medicine, 114(1), 91-96.

14. Daubin C, Parienti JJ, Fradin S, Vabret A, Ramakers M, Terzi N, et al. Procalcitonin levels and bacterial aetiology among COPD patients admitted to the ICU with severe pneumonia: a prospective cohort study. BMC Infect Dis. 2009;9: 157.

15. Bang KM, Syamlal G, Mazurek JM. Prevalence of chronic obstructive pulmonary disease in the U.S. working population: An analysis of data from the 19972004 national health interview survey. COPD. 2009;6(5):380-387.

16. Farooqi N, Carlsson M, Haglin L, Sandström $T$ and Slinde F. (2018). "Energy expenditure in women and men with COPD". Clinical Nutrition ESPEN, 28(1), 171178.

17. Gonçalves I. et al. (2018). "Clinical and molecular markers in COPD”. Pulmonology, 24(4), 250-259.

18. Boixeda R, Baca S, Elias L, Capdevila JA, Vilà X, Mauri $\mathrm{M}$, Almirall J. Pneumonia as Comorbidity in Chronic Obstructive Pulmonary Disease (COPD). Differences Between Acute Exacerbation of COPD and Pneumonia in Patients With COPD. Arch Bronconeumol. 2014;50(12):514-520.

19. Shukla SD, Muller HK, Latham R, Sohal SS, Walters EH. Platelet-activating factor receptor (PAFr) is upregulated in small airways and alveoli of smokers and COPD patients. Respirology 2016;21:504-10.

20. Gupta N, Pinto LM, Morogan A, Bourbeau J. The COPD assessment test: a systematic review. Eur Respir J 2014;44:873-84.

21. Blakemore A, Dickens C, Guthrie E, et al. Depression and anxiety predict health-related quality of life in chronic obstructive pulmonary disease: systematic review and meta-analysis. Int J Chron Obstruct Pulmon Dis 2014;9:501-12.

22. Khakban A, Sin DD, FitzGerald JM, Ng R, Zafari Z, McManus B, Hollander Z, Marra CA, Sadatsafavi M. Ten-year trends in direct costs of COPD: A Populationbased study. Chest 2015;148(3):640-646.

23. Rennard S.I; Vestbo J. COPD: The dangerous underestimation 15\%. Lancet 2006; 367:1216.

24. Singh S, Loke YK, Furberg CD. Inhaled anticholinergics and risk of major adverse cardiovascular events in patients with chronic obstructive pulmonary disease: A systematic review and meta-analysis. JAMA. 2008;300(12):1439-1450.

25. Abascal-Bolado B, Novotny PJ, Sloan JA, et al. Forecasting COPD hospitalization in the clinic: optimizing the chronic respiratory questionnaire. Int $\mathrm{J}$ Chron Obstruct Pulmon Dis 2015;10:2295-301.

26. Osterling K, MacFadyen K, Gilbert R, Dechman G. The effects of high intensity exercise during pulmonary rehabilitation on ventilatory parameters in people with moderate to severe stable COPD: a systematic review. Int J Chron Obstruct Pulmon Dis 2014;9:1069-78. 
27. Gan WQ, FitzGerald JM, Carlsten C, Sadatsafavi M, Brauer M. Associations of ambient air pollution with chronic obstructive pulmonary disease hospitalization and mortality. Am J Respir Crit Care Med. 2013;187(7):721-727. 